\title{
REAJUSTES DE LA VIOLENCIA EN UNA NOVELA, SU ADAPTACIÓN AL CINE Y UN REMAKE: EL SECRETO DE SUS OJOS
}

Readjustments of violence in a novel, its film adaptation and a remake: El secreto de sus ojos

\author{
RAFAEL MALPARTIDA TIRADO \\ UNIVERSIDAD DE MÁLAGA (ESPAÑA) \\ rmal@uma.es https://orcid.org/0000-0001-8438-9014
}

RECIBIDO: 19 DE JUNIO DE 2020 ACEPTADO: 30 DE OCTUBRE DE 2020

RESUMEN: En este trabajo se propone atender a un aspecto poco transitado en los estudios sobre transtextualidad: el tránsito de un texto literario a uno fílmico (El secreto de sus ojos) y la relación que establecen con un remake (El secreto de una obsesión), adoptando una tipología que contempla las categorías de la readaptación, el remake simple y la adaptación compuesta o mixta. Se incide para ello en la representación de la violencia, de acuerdo con la distinción postulada por Steven Pinker (que sigue a Thomas Hobbes) sobre las causas del conflicto humano, y se considera, por una parte, la construcción de los personajes, y por otra, la forma en que se muestran las imágenes. De este modo, se analizan los necesarios reajustes que se llevan a cabo en dos contextos muy distintos: la etapa previa a la Dictadura Militar Argentina de 1976 (término en el que se mueven de forma variable la novela de Sacheri de 2005 y la película de Campanella de 2009) y la hipervigilancia antiterrorista tras los atentados del 11-S (en la versión de Billy Ray de 2015).

PALABRAS CLAVE: Adaptación fílmica, remake, Sacheri, Campanella, Ray.

ABSTRACT: This paper deals with an aspect rarely explored in Transtextuality Studies: the relationship between a literary text and its film adaptation ( $E l$ secreto de sus ojos) with a remake (Secret of Their Eyes). This analysis considers the categories of readaptation, simple remake and compound or mixed adaptation. For this purpose, it focuses on (1) the representation of violence, in accordance with the distinction proposed by Steven Pinker (according to Hobbes) on the causes of human conflict, (2) on the construction of the characters, and (3) on how images are shown. In this way, the necessary readjustments that are carried out in two very different historical contexts are analyzed: the situation prior to the Argentine Military Dictatorship of 1976 (where Sacheri's novel and Campanella's film are set) and the anti-terrorist hypervigilance after the attacks of September 11th (in Billy Ray's version of 2015).

KEYWORDS: Film Adaptation, remake, Sacheri, Campanella, Ray. 


\section{INTRODUCCIÓN 1}

Si segundas partes, de acuerdo con el inveterado tópico (y con la sentencia traída por un tal Sansón Carrasco), nunca fueron buenas (y en el caso del cine, El padrino II es la excepción que, según parece, confirma la regla), los remakes ya son intolerables. El lugar común, que ha afectado tanto a la literatura como al cine cuando estos generan discursos fílmicos "derivados", sitúa el concepto de originalidad como eje rector y desestima todo lo que proceda explícitamente de un discurso previo.

Además, parece que a menudo se aplica al remake el mismo error metodológico que a la adaptación literaria: emplear el criterio de la fidelidad. En discursos "derivados", todo lo que se aparte del primer texto se considera una desviación y una desvirtuación. Y sucede a menudo que, como indica sagazmente Stam, "la crítica de la adaptación provee una serie de 'dilemas' y de 'círculos viciosos'. Una película 'fiel' es vista como poco creativa, pero una película 'no fiel' es una traición vergonzosa al original. [...] Parece como si el adaptador nunca pudiera ganar” (2014: 31).

Seguro que el lector habrá oído o leído aquella cantinela de que "el libro me gustó más" o "la película destrozó al libro", pero también que el remake hizo lo mismo con la película de la que parte. En el caso que nos ocupa, si el filme El secreto de sus ojos fue muy aplaudido (con los matices que veremos más adelante), seguramente porque el texto en el que se basaba no era por entonces demasiado conocido y la comparación no se efectuó in fieri, el remake estadounidense fue, en cambio, muy mal recibido ${ }^{2}$, pero conviene tasarlo en lo que atañe al diálogo que establece con el primer filme y teniendo en cuenta el nuevo contexto en el que surge respecto al modo de encauzar y mostrar la violencia.

$\mathrm{Al}$ espectador de a pie (y no digamos al crítico furibundo) probablemente no le parecerá bien que se dignifique mediante el análisis comparativo este remake; en cambio, en el ámbito de la investigación la tarea de comprender estos reajustes (de personajes, argumentos, representaciones visuales) resulta muy fecunda. Y más productiva, desde luego, que vilipendiar el remake porque se aparta de la otra película o (y esto es lo paradójico, como sintetizaba Stam) por lo contrario: por parecerse a ella.

La ampliación exegética a las series (Cascajosa, 2006) y a modos muy diversos de reescrituras (Felipe y Gómez, 2008) e incluso transescrituras (Pérez Bowie y Pardo, 2015), contribuye a rescatar para el estudio los remakes y otros discursos "derivados". Términos como el de trasvases culturales (Sánchez Noriega, 2000: 23-28), el de sinergia (Cascajosa, 2006: 340) o incluso el de mapa transtextual (Peña Ardid, 2020: 98) son muy útiles para este cometido, lejos ya de un fidelity criticism que no ha hecho sino erigirse, de forma notablemente improductiva,

\footnotetext{
1 Este trabajo se inscribe en el Proyecto de Investigación Reescrituras de la novela en el cine y la ficción televisiva (I Plan Propio de Investigación y Transferencia de la Universidad de Málaga).

2 Hay que diferenciar, no obstante, la crítica "de urgencia", como la de Boyero, que en este caso se encoleriza, sin más, preguntándose desde el propio título “Otro remake. ¿Y para qué?” (14/04/2016), con la investigación de más largo recorrido y ya más sosegada, como la que efectúa Roa para este mismo remake (2017).
} 
en máquina punitoria, en perspicaz detector de mentiras y alteraciones, en el albacea de títulos de propiedad intelectual, en guardián afanoso de los textos, como si aprendiera reglas mnemotécnicas y las expusiera para su vano lucimiento. (Wolf, 2001: 21) ${ }^{3}$

Y en el caso de El secreto de sus ojos, con contextos de producción muy distintos, la clave la aporta de nuevo Stam:

la adaptación es un trabajo de reacentuación, donde una obra fuente es reinterpretada a través de nuevas retículas y discursos. Cada retícula, al revelar aspectos del texto fuente, también revela algo sobre los discursos del ambiente en el momento de la reacentuación. (2014: 108)

Lo que propongo es, por tanto, que si como filme considerado en sí mismo este remake tal vez no parezca muy logrado, es en el cotejo con la novela y el anterior filme donde cobran relieve los elementos que incorpora y resulta así de mayor interés. Esta puesta en serie permite entender mejor las relaciones de transtextualidad, y en el caso de El secreto de sus ojos cómo se producen reajustes en la violencia desde una novela hasta su adaptación (ambas en torno a una misma circunstancia histórica) y de ahí a un remake (con cambio radical de contexto).

\section{FUNDAMENTO DE LAS RELACIONES ENTRE LOS TRES TEXTOS}

Lo primero que debemos establecer, a la hora de analizar los vínculos entre los tres textos (la novela de Eduardo Sacheri, publicada en 2005 como La pregunta de sus ojos, pero a la que me referiré por el título que recibió desde 2009, El secreto de sus ojos; la película homónima de Juan José Campanella de 2009; y la de Billy Ray de 2015 Secret in Their Eyes, que en España se llamó El secreto de una obsesión), es si el filme estadounidense constituye:

a) una nueva adaptación de la novela;

b) un remake de la película;

c) una adaptación compuesta o mixta de ambos textos, el literario y el fílmico.

Es este último un concepto muy sugestivo por el que me vengo interesando desde hace varios años y creo que la mixtura como forma de reescritura fílmico-literaria es un fenómeno relacionado con la transtextualidad y el comparatismo que aún no ha sido suficientemente explorado a pesar de lo revelador que puede resultar. Cuando he abordado esta cuestión, siempre

\footnotetext{
${ }^{3}$ Lo que propone muy razonablemente Wolf es que, en cambio, "el único modo de pensar la literatura y el cine es despojándolos de toda atribución positiva o negativa, extirpar la discusión de toda jerarquización entre origen y decadencia" (2001: 29), de forma que, desde un punto de vista metodológico, "la interrogación [...] debería centrarse en los motivos de los cambios y las persistencias, y en los efectos que producen" (2001: 22), y no en el supuesto grado de "desviación". Liquida la cuestión el hecho de que toda adaptación o "transposición requiere al menos una franja de independencia que podrá ensancharse o angostarse según el criterio elegido, pero que es consustancial a la operación misma de transponer" (2001: 30). Como señala García Jambrina, nos encontramos ante una operación intersemiótica, lo que supone actuar de forma "selectiva y recreadora", con todo lo que ello representa a la hora de estudiarla (1998: 150). El empleo de los términos bipotexto e hipertexto, de acuerdo con la teoría de Genette (1989), también podría contribuir a limar jerarquizaciones en este ámbito de estudio comparatístico. Para descartar la aproximación del fidelity criticism en este ámbito de estudio, conviene tener en cuenta, además del demoledor libro de Stam (2014), el artículo de Zecchi, cuyo tercer epígrafe se titula "Superando la fidelidad: códigos, estructuras e intertextualidades" (2012: 32-41).
} 
me he encontrado con auténticas sorpresas sobre el modo en que dialogan obras de diferente tejido (y aquí la etimología de texto nos ayuda a entender el concepto) y sobre las maneras en que se reactivan sus relaciones ${ }^{4}$.

El secreto de sus ojos ofrece una primera lectura de sesgo comercial que nos podría conducir a reflexionar sobre los mecanismos publicitarios que emergen cada vez que aparece una revisitación y cómo la industria en torno a la literatura se encarama a la otra industria, la del cine, para dar nueva vida (en forma de ventas, claro) al texto matriz. Que la novela publicada modestamente en Buenos Aires por la editorial Galerna se trasladara, tras el éxito de su adaptación al cine (Óscar al mejor filme de lengua no inglesa incluido), a la multinacional de Santillana y recibiera desde entonces no solo el mismo título de la película, trocando la pregunta por el secreto, sino el cartel de esta en la cubierta, es algo muy habitual en estos procesos de reconocimiento y de relanzamiento de un texto literario espléndido como el de Sacheri pero que apenas había obtenido resonancia hasta que Campanella decidió emplearlo (con la colaboración en el guion del propio literato) para construir su película. Seguro que el lector recuerda muchos casos de novelas que se venden con este reclamo (totalmente legítimo, desde luego) y habrá tenido entre sus manos múltiples ejemplos. No puedo objetar nada cuando veo a menudo cubiertas descafeinadas o, por vía contraria, diseños horrendos por saturación de formas y colores, mientras que mi edición de 2009, gracias al cine, ofrece los rostros de Ricardo Darín y Soledad Villamil, ambos con los ojos cerrados y bosquejando un beso tan deseado como inalcanzable, como precioso motivo central.

Lo que sí llama la atención, en cambio, es que desde que surgió el filme de Billy Ray se ha reeditado la novela (ya no en Alfaguara, sino, fruto de la absorción editorial, bajo otra multinacional, Penguin Random House, concretamente en DeBolsillo) con una cubierta que reproduce el cartel de la película protagonizada por Nicole Kidman, Julia Roberts y Chiwetel Ejiofor, con la leyenda "Llevada a la pantalla como Secretos de una obsesión". ¿Y por qué esta nueva cubierta sí debe llamar la atención, cuando se trata, en apariencia, del mismo mecanismo que ya se activó con el filme de Campanella? La respuesta es muy sencilla: porque nadie se molestó en comprobar si la nueva película es, en puridad, una adaptación de la novela de Sacheri. El filme de Billy Ray, en realidad, no incorpora ningún elemento del texto literario que no estuviera ya en la película de Campanella, por lo que no es ni una adaptación pura de la novela ni una adaptación mixta; se trata, así pues, de un remake sin más 5 . De hecho, es muy probable que el artífice del guion del filme estadounidense no haya leído jamás la novela de Sacheri; le bastó con tomar como punto de referencia la película que sí estaba basada en dicha novela. Y he sacado a colación el nombre de los actores porque el reclamo de figuras tan conocidas parece insoslayable a la hora

\footnotetext{
${ }^{4}$ He tenido la oportunidad de comprobarlo con casos tan variopintos como las adaptaciones múltiples de obras de Tsuruya Namboku IV (Tokaido Yotsuya Kaidan), Gógol (el cuento “El Viyi”), William Riley Burnett (El último refugio), Geoffrey Homes (Eleven mi horca) o Fritz Leiber (Esposa hechicera). Dada la complejidad de estas redes de relectura, se puede obrar como en la ecdótica, elaborando stemmas que den cuenta de la genealogía de las transformaciones textuales.

${ }^{5}$ Creo, por tanto, que se confunde Roa cuando afirma que "está basada tanto en la película El secreto de sus ojos como en el libro La pregunta de sus ojos" (2017: 149). Los créditos finales son, además, inequívocos: "Based on the film El secreto de sus ojos, written by Juan José Campanella and Eduardo Sacheri”. La presencia del novelista en El secreto de una obsesión procede del guion, no de su obra literaria.
} 
de relanzar un texto literario, por más que la relación entre novela y filme no fuera, en ese caso, directa, sino exclusivamente a través de la mediación de otra película.

Al margen de estas operaciones de tipo publicitario, que aquí revelan una inexactitud o una mixtificación (tome el lector el término que prefiera), cada vez que surge un nuevo texto fílmico podemos leer tanto la novela como esos mismos textos fílmicos de modo diferente. Ya nada es igual, porque se incorporan sugestiones en la recepción "cruzada". Y la lectura y relectura (en este caso, como acabamos de establecer desde el punto de vista "genealógico", de Sacheri a Campanella; de Campanella a Ray), bajo el eje de lo que podríamos denominar "reajustes" de la violencia, es lo que voy a proponer a continuación.

\section{PUNTO DE VISTA DE LA CONSTRUCCIÓN DEL PERSONAJE}

Por tomar un referente teórico suficientemente flexible para ordenar las ideas en torno a la manifestación de la violencia, me parece idónea la lectura que Pinker (2003: 462-489) realiza del asunto a partir de Hobbes y su Leviatán. Las causas del conflicto, de la violencia entre los hombres 7 , se pueden clasificar, según Hobbes, en la competencia, la inseguridad y la gloria. Aunque estos términos sean bastante imprecisos, diríase que los tres momentos clave en que activa la violencia el personaje de Isidoro Gómez (Javier Godino) en el filme de Campanella responden precisamente a cada uno de ellos: la violación y asesinato de Liliana, a su competencia con el marido de esta; el ataque frustrado a Irene (Soledad Villamil) en el interrogatorio, a la inseguridad que ella le provoca para que confiese; la amenaza en el ascensor, a la ostentación de un poder recién adquirido.

El espectador recuerda y asocia esas tres actuaciones, diseminadas en momentos estratégicos, y poca duda puede caberle sobre el comportamiento del abyecto personaje y sus motivaciones. En cambio, al personaje de Isidoro Gómez en la novela de Sacheri no se le marcan esos tres hitos del mismo modo (de hecho, el segundo se atenúa considerablemente y el tercero no aparece) e incluso se le presenta como víctima cuando es encarcelado tras su detención por violación y asesinato. ¿Es esa, entonces, una manera de simplificar su carácter, como a menudo se piensa, por parte del cine? Creo que no, dado que el propio Sacheri declaró que sus personajes "se complejizaron con la mirada de Campanella" (Repar, 18/08/2009: s. p.). Limitar las acciones de Isidoro no significa que se limite al personaje como creación llena de espesor, solo que se le reduce como actante. Es frecuente que el cine, al acotar el radio de acción de un personaje, esté enfatizando parte de su carácter, y la concentración o intensificación no es un demérito; bien

\footnotetext{
${ }^{6}$ Se entiende esta recurrencia porque la tesis de Pinker se sustenta en que "muchos intelectuales han apartado la vista de la lógica evolutiva de la violencia, temerosos de que reconocerla equivalga a aceptarla o, incluso, aprobarla. En su lugar, han seguido la cómoda ficción del Buen Salvaje, donde la violencia es un producto arbitrario del aprendizaje o un agente patógeno que nos invade desde el exterior. Pero negar la lógica de la violencia propicia que se olvide lo fácilmente que ésta puede estallar, e ignorar las partes de la mente que activan la violencia propicia que se olviden las partes que la pueden sofocar. Con la violencia, como con otras muchas preocupaciones, el problema es la naturaleza humana, pero, al mismo tiempo, la naturaleza humana es la solución” (2003: 488-489).

${ }^{7} \mathrm{Y}$ aquí debemos hablar de hombres no entendiendo especie humana, sino atendiendo, en especial, al sector masculino, responsable principal de la violencia (Pinker, 2003: 458). Véase también, por citar un excepcional referente fílmico sustentado en esta tesis, la película de Nadine Labaki ¿Y abora adónde vamos? (2011), o en contexto muy diferente, la Roma (2018) de Alfonso Cuarón.
} 
empleadas, pueden constituir, por el contrario, todo un acierto. Es más, esa construcción del personaje de Isidoro Gómez desde la vileza sin ambages, se pone incluso en parangón con la configuración del protagonista, Benjamín (Ricardo Darín): es aterrador que los dos miren del mismo modo a Liliana y a Irene, respectivamente, y que esa vinculación desatasque el caso criminal, como se incide en el filme mediante realce argumental de lo que propone la novela.

Volviendo a Pinker y su recurrencia a Hobbes, si esas son las tres causas de la violencia, su prevención consiste en la creación de "un órgano de gobierno al que se haya concedido el monopolio del uso legítimo de la violencia" (2003: 480). Parece muy sencillo en condiciones ideales: permitir su empleo sancionador y, en consecuencia, disuasorio, podría mitigar el uso de la violencia. La paradoja reside, como tan frecuentemente ha delatado la Historia con mayúscula y como propone en su dimensión criminal esta historia con minúscula contada en El secreto de sus ojos, en que dicho uso legítimo de la violencia por parte de un órgano de gobierno se termina poniendo al servicio no de la justicia, sino de la iniquidad. Es lo que Žižek denomina violencia "sistémica", que delata "las consecuencias a menudo catastróficas del funcionamiento homogéneo de nuestros sistemas económico y político" (2009: 10) ${ }^{8}$.

Y ejercer la violencia desde el gobierno o con el amparo o connivencia de este mismo conduce a la impunidad y de ahí al exhibicionismo. Téngase en cuenta que al amparo de equívocas y arteras denominaciones, se intentaba legitimar esa violencia, empezando por el llamado "Proceso de reorganización nacional" ("la Argentina que se viene", como dice el personaje de Romano en el filme), y que una manifestación en particular de dicha violencia, la desaparición forzada de personas, "combinó información y secreto, ocultación y visibilidad” (Feld, 2015: 688)9. Como bien sintetiza Robben,

para los grupos implicados son fundamentales los términos con que se hace referencia a la violencia política acaecida en Argentina durante los años setenta (ya sea «guerra contrarrevolucionaria», «guerra civil» o «terrorismo de Estado»), pues cada una de estas designaciones lleva implícita una serie de juicios morales e históricos que puede convertir a los patriotas en opresores, a las víctimas en ideólogos o a los héroes en subversores. (2002: 142)

Así, resulta llamativo el modo en que se describe a la Triple A (la Alianza Anticomunista Argentina, el grupo paramilitar que campó a sus anchas durante los años precedentes a la Dictadura Militar de 1976 y durante esta) en la novela de Sacheri, y lo hace, para más inri, un agente de la ley, un comisario, que no puede hacer nada contra ellos salvo ayudar a Benjamín a huir de su amenaza:

\footnotetext{
8 Hemos de tener en consideración que se trata de una "violencia inherente al sistema: no sólo de violencia física directa, sino también de las más sutiles formas de coerción que imponen relaciones de dominación y explotación, incluyendo la amenaza de la violencia” (Žižek, 2009: 20). Sobre esta violencia ejercida por el Estado, véase el planteamiento de Arendt, para quien, "si comenzamos una discusión sobre el fenómeno del poder, descubrimos pronto que existe un acuerdo entre todos los teóricos políticos, de la Izquierda a la Derecha, según el cual la violencia no es sino la más flagrante manifestación de poder" (2006: 48).

${ }^{9}$ Feld, Claudia. "Imagen y testimonio frente a la desaparición forzada de personas en la Argentina de la transición". Kamchatk.a. Revista de análisis cultural 6 (2015): 687-715.
} 
Se topó con uno de esos grupos de forajidos que usa el gobierno, mi amigo. [...] Todo concuerda. La impunidad, el salvajismo, el actuar en barra (la vecina del departamento B, no sé si la conoce, me terminó reconociendo, después de un largo trabajito de ablande, que por la mirilla vio pasar a cuatro. [...] Usted no es un militante, no es un hombre público. No trabaja en un tema que a los militares les interese (no creo que la Justicia les importe un pito, de hecho). ¿Qué razón puede haber entonces para que le caiga encima una banda como esa? Tenían que tener algo con usted, algo viejo, algo personal... [...] Primero temí que fuera muy difícil averiguar algo de estos tipos que andan en los servicios de inteligencia, y toda esa mano. Capaz que en un país serio esas organizaciones son herméticas. Bah, supongo. Pero acá tienen más agujeros que un colador de té, fijese. Porque aparte les gusta mostrarse, ¿'sabe? Eso de andar en autos sin chapas, con lentes oscuros, exhibiendo sus Itacas como si fueran sus... ya sabe qué. [...] Así que resultan bastante fáciles de ubicar. Dos o tres conversaciones poniendo cara de boludo maravillado dispuesto a escuchar sus pioladas, y yo ya tenía poco menos que un organigrama de cómo funcionan. [...] Si no fueran unos sanguinarios hijos de puta, serían para cagarse de la risa. (Sacheri, 2009: 250-252)

El comisario se ceba mediante un relato burlesco con esos "forajidos" como ya lo había hecho una y otra vez el propio narrador-protagonista, Benjamín, con el propio aparato de la Justicia al que él mismo pertenece. El panorama es, por tanto, desolador, pero emerge a tiempo un ingrediente atenuador: la novela de Sacheri sabe incorporar sutil y equilibradamente un componente humorístico que en el filme está desplazado a otros fines y gravita, sobre todo, en torno a la célebre vis cómica de Guillermo Francella.

La película realza el aspecto exhibicionista que representa el personaje de Isidoro Gómez, antes y después de unirse al grupo paramilitar. Veámoslo para los tres citados momentos clave: tras la violación y asesinato de Liliana, no oculta su cadáver, sino que lo deja en la cama y lo muestra; en el interrogatorio, no le basta con admitir, picando en el anzuelo que le lanza Irene, que él sí es "lo bastante hombre" como para haber hecho eso, sino que enseña el pene como refrendo y se dirige hacia ella para demostrarle su virilidad; en el ascensor, hace alarde de que puede cargar un arma impunemente y amenaza así a los protagonistas ${ }^{10}$. No es difícil notar en este último añadido del filme una asociación de los conceptos de violencia, poder y sexualidad desde un prisma simbólico ${ }^{11}$. No olvidemos lo que decía el comisario en la novela: "exhibiendo sus Itacas como si fueran sus... ya sabe qué" (Sacheri, 2009: 252).

10 Hemos de tener en cuenta, como señala Peris Blanes, que este tipo de violencia represiva, a menudo tácita, procura "generar el terror necesario para que la ruptura del tejido social careciera de mayores resistencias", de ahí que, por ejemplo, una de las películas señeras sobre el tema como Garage Olimpo tenga que "aludir mediante elusiones, silencios, vacíos y omisiones a aquellas zonas de la realidad que estaba tratando de representar" (2008: s. p.).

${ }^{11}$ En esta línea se inscribe lo que explica Acosta Larroca: "ahora el cazado pasa a ser el cazador, el que tiene en sus manos y a punta de pistola inclusive (ahora sí de metal, a diferencia de la que sostiene en la escena del interrogatorio) el poder" (2009: 63). Y lo cito porque, una vez comprobado que no estoy incurriendo en la frecuente sobreinterpretación (o, al menos, que la asociación de ideas la ha realizado alguien más) de que todo objeto alargado que aparece en un relato es un símbolo fálico, resulta escalofriante la vinculación de esa pistola que carga Isidoro Gómez con sus actos de violación y asesinato; de hecho, lo que exhibe el canalla a través de esa pistola es la impunidad ante lo que hizo a Liliana (primer signo de poder, aquí "retroactivo") y la inmunidad ante el intento de la Justicia (encarnada aquí por Benjamín e Irene, paralizados de miedo en el ascensor) por detenerlo de nuevo (segundo signo de poder, en este caso "prospectivo"). 


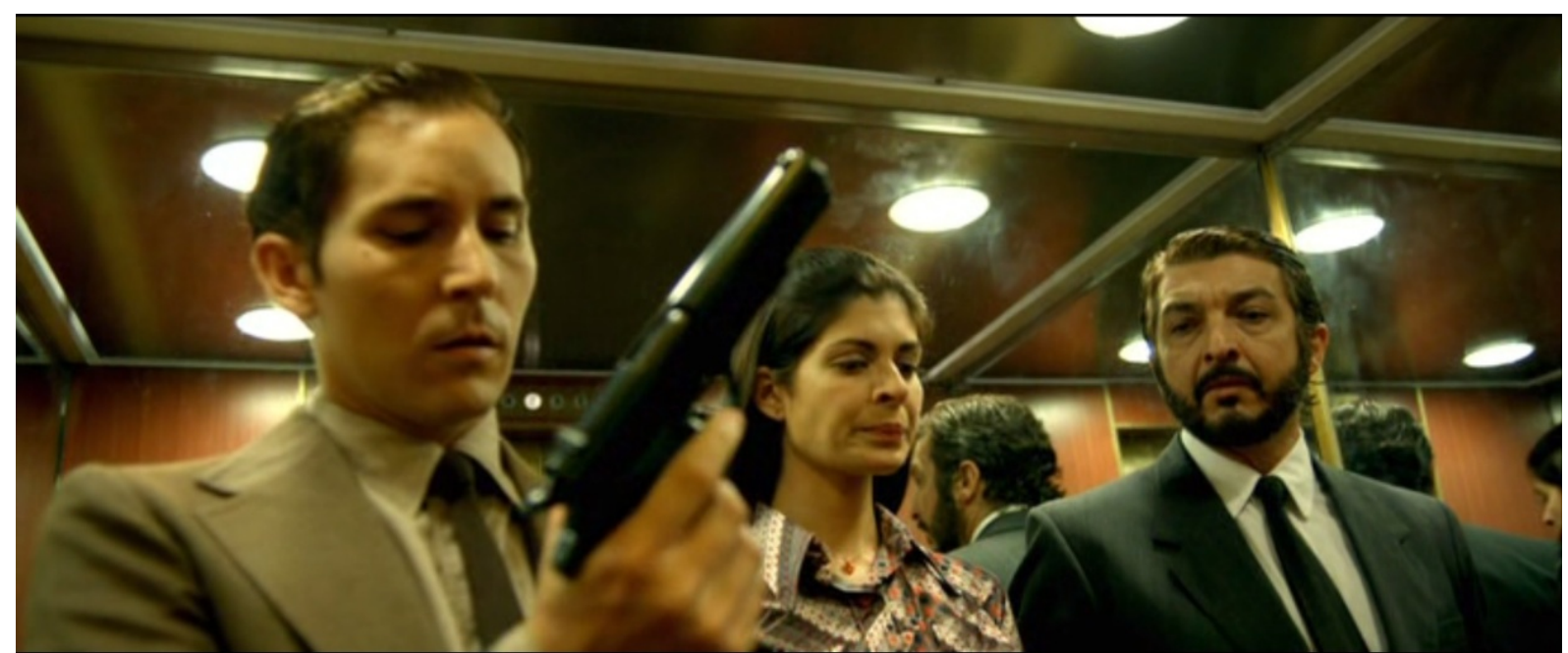

Conceptualmente, coinciden en esto la novela de Sacheri y su adaptación: como sintetiza Dillon, "en esta película el Estado es, sobre todo, un refugio para los peores criminales, un ámbito donde ascienden los asesinos y los corruptos" (2018: 8), y podría aplicarse, como marco de actuación de Isidoro Gómez, a ambos textos.

En cambio, si analizamos brevemente cómo es el violador y asesino del remake, Anzor Marzin (Joe Cole), su comportamiento es muy distinto. Para empezar, se ha reducido notablemente su carácter exhibicionista. Si repasamos los tres hitos de la violencia que estamos tomando como ejemplo, Marzin no es el ser frío y calculador que deja a la víctima expuesta, pues esconde el cadáver de la joven Carolyn en un contenedor e intenta borrar las huellas de su crimen con lejía; en el interrogatorio, sucumbe más fácilmente y no solo por una provocación de tipo sexual, sino también porque se pone en duda su inteligencia; por último, en el ascensor, donde no hace alarde de arma alguna, se limita a proferir una risilla estúpida como diciendo "Me he librado”. Personaje de trazo más grueso que el del Isidoro Gómez del filme argentino, obra más como un mequetrefe con ínfulas de tornarse de informador en agente, y no beneficia a la delineación de su iniquidad que se dedique a escribir cómics, que viva con una stripper y que se haga llamar "Pac-Man". Isidoro Gómez, que había sido "noviecito" de Liliana, según las palabras de su madre en el filme, parece obrar con premeditación y su personalidad criminal está más pulida, lo que contribuye a trabar mejor la trama criminal en torno a su captura y las complejas relaciones de los personajes que gravitan en torno a él.

\section{PUNTO DE VISTA DE LA MOSTRACIÓN DE LAS IMÁGENES}

Para analizar no ya al actante y su actitud, sino sus acciones y sus representaciones, creo que el punto de partida idóneo, tratándose de un caso de violación como resorte de la trama criminal, es la tipología que propone Zecchi (2006) para este asunto en el cine. Pero leamos primero cómo se describe el cuerpo ya sin vida de Liliana Colotto y las reacciones de los "espectadores" en la novela de Sacheri:

Igual no había modo de llegar hasta él, porque la cama ocupaba casi todo el recinto, y junto a ella yacía el cadáver, y cuando abrieron el surco supuse que si no quería pasar por blando tenía que detenerme a mirar a la muerta. 
Sabía que era una mujer porque el policía que había llamado al Juzgado a las ocho y cinco me había comunicado, en esa extraña jerga que los policías emplean al parecer con cierto deleite, que se trataba de «un NN femenino joven». Esa supuesta neutralidad del lenguaje, esa suposición de que estaban hablando en términos forenses, a veces me causaba gracia, pero en general me producía fastidio. ¿Por qué no decir directamente que la víctima era una mujer joven de la que aún ignoraban el nombre, y que parecía tener poco más de veinte años?

Sospeché que había sido hermosa, porque más allá del feo color cárdeno que había tomado su piel mientras la estrangulaban, y de la deformación esperable en un rostro congelado en la crispación del horror y la falta de oxígeno, existía en esa chica una majestad que ni siquiera una muerte horrible había podido borrar. Tuve la certeza bochornosa de que el crecido número de policías que andaban pululando por ahí tenía que ver precisamente con eso, con que fuera hermosa y con que estuviese desnuda, tirada de mal modo boca arriba a los pies de la cama sobre el parqué claro del dormitorio, y con que a varios de los que estaban ahí les encantaba mirarla impunemente. (2009: 39-40)

Sacheri maneja con pericia, a través de la voz del narrador-protagonista (se trata de uno de los capítulos en que este toma las riendas del relato porque contienen la novela que está escribiendo Benjamín), segmentos digresivos que alterna y concreta perfectamente con la observación del personaje. El retrato que ofrece de la actuación policial, primero por el protocolo descarnado y seguidamente por la actividad de los mirones, es desolador. Con protectores del orden como esos policías de la escena del crimen, habríamos de preguntarnos quién nos protege de ellos mismos. Frente a esa estampa del texto literario, que incide más en las miradas que en lo mirado, hay en el filme un sumo respeto mediante cierta asepsia formal ${ }^{12}$. Y es aquí donde Zecchi proporciona las claves para su análisis: de manera semejante a los filmes de Mañá y Bollaín con que ella ejemplifica, se produce un "intento de deserotizar la exhibición del cuerpo desnudo femenino" (2006: 125), y el espanto de lo mostrado se alinea con la mirada de espanto del protagonista $^{13}$. Si se hubiera introducido, como en la novela, a los policías mirones (y, con ellos, la idea de erotización), el efecto no se habría producido.

Por tanto, es en lo tonal donde más difieren las secuencias de sentido. Y, desde luego, no se puede acusar a Campanella de sensiblería, como se ha hecho a menudo, porque la secuencia es un dechado de recursos para incidir en lo descarnado de las imágenes y en el impacto que provocan, a través de la "visión-con", en el protagonista, al que debe adherirse emocionalmente, desde ese instante, el espectador. A partir de ahí, la causa sobre Liliana Colotto es también nuestra causa.

Si pasamos al remake, el cadáver es trasladado, como ya indiqué, a un basurero: se oculta. Isidoro Gómez, sin embargo, lo deja ahí, en la cama: lo muestra. Se trata, como vimos, de una forma de exhibición. Y como en el remake se encuentra en el lugar del descubrimiento su propia madre, la agente del FBI Jessica Cob (Julia Roberts), hay un momento de tensión dramática que

\footnotetext{
12 No puedo coincidir, en consecuencia, con la lectura que realiza Navarro basándose precisamente en ese momento del filme, en el que percibe "una dramática morbosidad" y que le lleva a sustentar su tesis de que "Espósito es incapaz [...] de declarar su amor a Irene [...] porque en realidad a quien ama desesperadamente es a la muerta: Irene se convierte en un fantasma, en una imagen especular viva de la difunta" (2009: 17). Destaco, no obstante, sus palabras, porque a partir de esa idea matriz desacertada sí me parece sugestiva la idea derivada de que "Morales es una especie de alter ego siniestro de Espósito" (2009: 17).

13 A este propósito, es muy sugerente la lectura de Karageorgon-Bastea, que se refiere a una "contra-idealidad" al contrastar "la belleza de la forma" y "algo de plasticidad" con el horrendo crimen, "recordatorio del fracaso e ineptitud de aquellos cuya labor es preservar la idealidad en y de la polis" (2018: 300).
} 
contrasta con la frialdad, deliberada, desde luego, con que se encauza en el filme argentino la secuencia.

Si ese cambio deriva de la diferente configuración de los personajes (tanto actitudinal en el caso de Marzin como actancial en el caso de ella), hay una razón de muy distinto tenor para que en el interrogatorio el asesino muestre el pene a los personajes pero no lo veamos los espectadores porque se deja fuera de campo. El motivo parece evidente: en el remake se interponen códigos más estrictos de autocensura, propios de la industria hollywoodiense, frente a la mayor liberalidad que opera en otros contextos de producción como el argentino (en coproducción, en este caso, con España).

Tenemos, por tanto, un ejemplo de reajuste de la violencia que obedece a imperativos puramente narrativos (la reacción en cadena de actantes que representa el remake) y otro que se debe a un componente moralizante (el cambio de contexto de producción).

\section{DEL TEMA DE LA JUSTICIA PERSONAL AL TEMA DEL CARGO DE CONCIENCIA}

El castigo por venganza personal del desenlace suscitó una encendida polémica en cuanto se estrenó el filme de Campanella ${ }^{14}$. Así lo sintetiza Lillo y lo deslinda muy bien respecto a las acciones de los dos personajes, el captor y el finalmente cómplice:

El gesto de Morales remueve estos deseos básicos instintuales de venganza personal en el espectador, que puede quedar reconfortado a pesar de lo monstruoso y violento del gesto, aunque sea provisoriamente. Pero de efectos más perniciosos desde el punto de vista político es la representación de la reacción de Benjamín ante el descubrimiento atroz de la cárcel clandestina. (2017: 151)

Si en la novela el desenlace se presenta algo atenuado con la hermosa idea de las cartas post mortem de Ricardo Morales, de manera que todo el proceso está ya acabado, en el filme resulta impactante acompañar al protagonista y presenciar in situ el particular cautiverio. Es espeluznante, además, lo que ruega el preso a Benjamín: que le diga al carcelero que al menos le hable.

¿Por qué el representante de la Justicia, Benjamín, encubre el crimen que representa esa captura y ese presidio? Porque lo que deduce de esa vida de Morales consagrada a custodiar al

\footnotetext{
14 Esta polémica a flor de piel, justo después del estreno, puede seguirse en las páginas de la revista argentina El Amante. Véanse sobre todo los artículos de Rojas, para quien "Espósito, el bueno, tiene un sentido de la justicia que excede a su voluntad. ¿De dónde salió ese bicho atípicamente argentino? ¿Y por qué entonces traiciona su propia naturaleza convirtiéndose en cómplice final de la vindicta privada de Morales? [...] ¿Por qué el cine insiste en reivindicar la venganza privada a contrapelo del reclamo de víctimas y familiares? ¿Por qué inventa una historia que contradice al presente de esos reclamos? Este cine manipula a ambas, torsiona los verosímiles irresponsablemente, sin otro objeto que pespuntear con brillosos golpes bajos las costuras de sus anécdotas" (2009: 21); y de Noriega, que matiza lo siguiente: "al confinar al asesino a esa cárcel clandestina perpetua, Morales se condena a sí mismo al rol de carcelero eterno: los dos son cara y ceca de una misma moneda, entrelazando sus vidas hasta el final. Si alguien queda cristalizado en el pasado, incapacitado para resolver su dolor y salir adelante, ése es el pobre Morales. Su resolución en la película es tan diametralmente opuesta a la que encaran Espósito e Irene, que parece problemático convertir a ese acto de venganza en el eje conceptual de la película” (2009: 17). En esta última línea, señala Ivachow que "si Espósito ha buscado la justicia desde los dispositivos de la ley y, quebrados éstos, desde una reparación literaria, Morales se le adelanta con su justicia única y personal, forjando desde su indómito mundo mental otra particular reparación histórica" (2009: 18).
} 
asesino de su esposa es que constituye un acto supremo de amor hacia ella. Es más, por atroz que sea tomarse la justicia por su mano de ese modo ("Perpetua, me dijo"), no solo lo entiende y respeta Benjamín, sino que constituye una lección de persistencia tras la cual se decide por fin a declararse a Irene ${ }^{15}$. Es terrible que de conceptos como el odio, el resentimiento o la venganza puedan engendrarse motivaciones relacionadas con el amor ( $\mathrm{y}$ no con uno cualquiera, pasajero o caprichoso, sino con el amor de toda una vida), pero es tal vez la lectura más atrayente de la novela de Sacheri, potenciada hasta extremos magistrales de ambigüedad y complejidad en la adaptación de Campanella, como apunté en otro lugar (Malpartida Tirado, 2011: 369-371).

Ray, que no encauza bien la trama amorosa, transita por otro camino, y es donde creo que difieren notablemente los dos filmes, como explica Roa: en el remake "los personajes no se enfrentan a sucesos que ocurren a desconocidos, sino que su estrecha relación con ellos es lo que los lanza a preocuparse, a sufrir" (2017: 153). Volvamos a la secuencia del ascensor para comprobarlo: cuando Jessica se queda a solas en su interior, rompe el espejo a culatazos y vemos el reflejo quebrado de su rostro. La imagen es muy reveladora de las intenciones del filme: se trata de una autolesión en términos simbólicos, premonitoria de la que va a efectuar de forma literal al emprender la caza y custodia del asesino. Y la rabia hacia este es también rabia hacia ella misma.

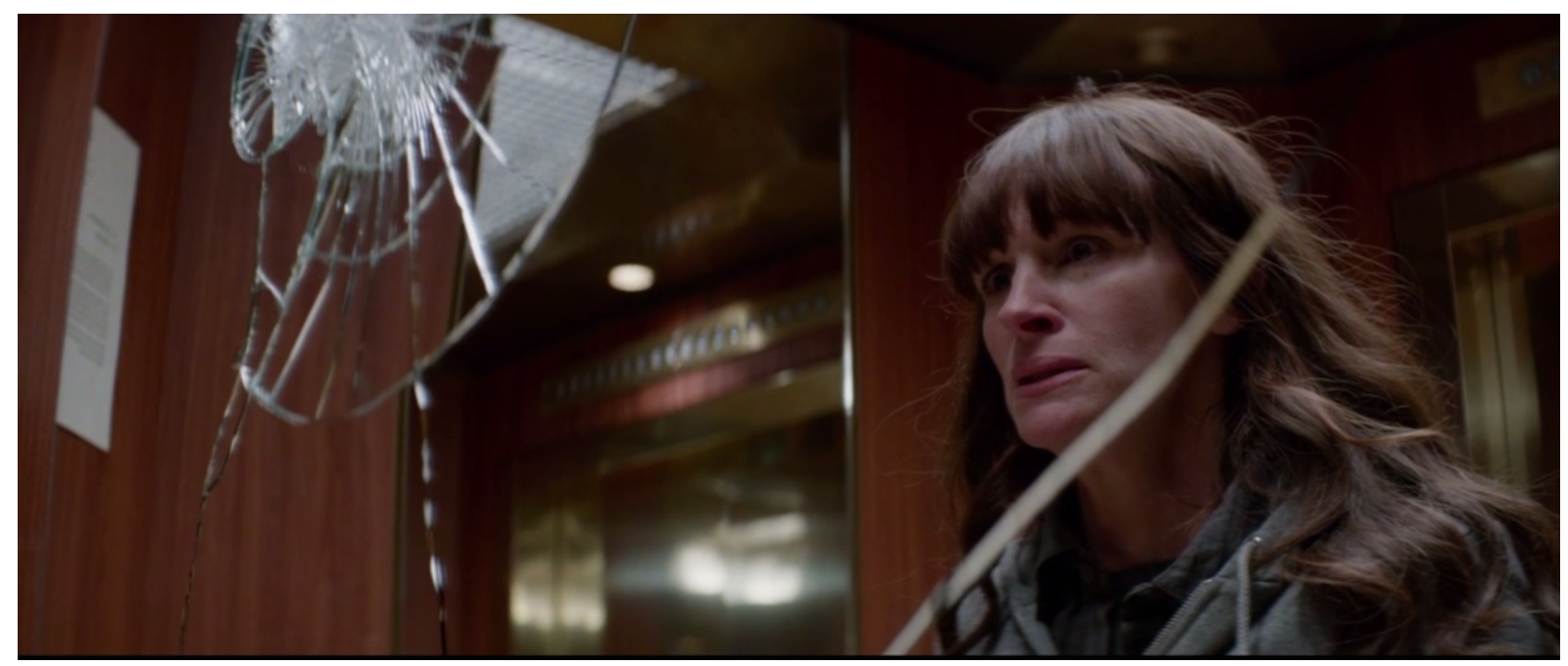

Aunque muy a menudo hemos estado desafortunados titulando películas, con La semilla del diablo como paradigma del disparate, la denominación El secreto de una obsesión para el mercado español refleja bien ese viraje. Y la obsesión no solo procede del deseo por atrapar al asesino y obtener justicia, como en el texto de Sacheri y su adaptación al cine, sino porque el cargo de conciencia se hace insoportable. Por eso, cuando se decide a actuar (y ahí interviene el espejo como signo de escisión, de duda, de toma de postura ante un conflicto interior) y toma cartas en el asunto, "este sentimiento de culpabilidad es lo que la motiva a asumir la penitencia de encarcelar al asesino y encarcelarse ella misma con él. Está expiando, no solo está haciendo justicia” (Roa, 2017: 153).

15 Como bien indica Ivachow a propósito de Morales, "su obsesión es un espejo veloz de la obsesión de Espósito" (2009: 18). 
Afecta, además, a los dos protagonistas, que a veces parecen competir sobre quién es más responsable de la muerte de Carolyn. Ella insistió a su hija para que fuera a un picnic donde la vio el asesino por primera vez; él había quedado con la joven para comprarle un pastel de cumpleaños a la madre, no pudo ir a la cita y dos horas después fue asesinada. Operó, desde luego, el azar, pero en lugar de pensar eso, a ambos les atormenta la idea de que contribuyeron decisivamente a la muerte de la chica.

De este reajuste proceden las diferencias en el desenlace, más notables de lo que a primera vista podría parecer: en Sacheri, el cautiverio no se muestra salvo por sus resultados (ambos, preso y guardián, mueren) y está más velado el factor sorpresa; en Campanella, representa una suerte de expiación pero también, de acuerdo con la lectura que prefiero del filme, está conectado con el amor y resulta impactante; en Ray, es un acto de autoflagelación en grado sumo. Como bien explica García-Reyes a propósito de la novela y del primer filme, "en ese ajuste de cuentas particular no se intuye redención alguna" y se produce "la dualidad de una doble condena, la del carcelero y la del preso" (2017: 103). En el remake se introduce además un cargo de conciencia obsesivo para los protagonistas y se debe producir la absolución y el alivio ("¿Perpetua también para ti?", le dice el protagonista masculino a Jessica). Por eso se liquida al asesino en cautiverio, una vez que se reencuentran los dos personajes que se creen responsables de la muerte de la joven, y resulta oportuno el gesto de él dejándole la pistola para que acabe con el preso y, de esa forma, con el sufrimiento expiatorio de ser su carcelera. Cuando suena fuera de campo el disparo, una bandada de pájaros echa a volar, signo inequívoco de liberación de la culpa. El cargo de conciencia es una carga, un lastre, y se ha soltado. Él cava la tumba, al frente del encuadre, mientras ella lo ejecuta en la casa. Ambos cooperan porque se creen partícipes de la muerte de la joven. Toda la secuencia está repleta de excelentes ideas desde un punto de vista conceptual y formal, y se resuelve, además, con parquedad de palabras, solución poco habitual en este tipo de desenlaces centrados en resortes psicológicos.

Creo que es necesario introducir una última consideración de tipo ideológico y en función de la recontextualización histórica. En el caso del primer filme, la repetición del modus operandi de la Triple A, es decir, "chupar", como se indica en la novela de Sacheri (2009: 253), por parte de Ricardo Morales, que se toma la justicia por mano propia, resultó insoportable para un sector de la crítica y del público porque, desde cierto punto de vista, la víctima se comportaba igual que los verdugos. Billy Ray, al reajustar hacia el clima de hipervigilancia post-11S, ¿propone un ejemplo de cargo de conciencia personal como representación o concreción de uno colectivo? Un libro de Lawrence Wright y su reciente adaptación homónima en forma de serie, The Looming Tower, han incidido en que aquel atentado (que ha marcado decisivamente lo que podríamos denominar "el orden internacional") pudo haberse evitado si las agencias de inteligencia hubieran cooperado entre ellas, en lugar de oponerse y de ocultarse información ${ }^{16}$.

El filme argentino no elude, desde luego, la cuestión política, pero recordemos que sus protagonistas participan de manera más tangencial en el mantenimiento del orden; en cambio, en el remake se trata de agentes del FBI que están vigilando una mezquita en una misión

\footnotetext{
16 Para empezar, según Wright, "el aspecto más aterrador de esta nueva amenaza era que casi nadie se la tomaba en serio" (2017: 15).
} 
antiterrorista. De este modo, al integrarse un componente profesional con uno privado, ¿se está planteando en el filme estadounidense una forma individual de ese cargo de conciencia colectivo? Se pudo evitar el mayor atentado de la Historia y también la violación y el asesinato de una joven. La terrible paradoja que encierra esta asociación es que ambas acciones entran en conflicto. Que se trate de la hija de Jessica, una de las agentes (y no de la esposa de un personaje ajeno, Ricardo Morales, como en la novela y en el primer filme), es el cambio actancial que motiva e integra estos dos elementos general y particular.

Como decía Haneke a propósito de Caché, "siempre hay una culpabilidad colectiva que puede conectarse con una historia personal y así quiero que se entienda en este filme" (MartínezCabeza y Espínola, 2012: 152); la película de Billy Ray no llega, desde luego, a esos niveles de imbricación del espléndido filme del realizador austríaco, pero si pensamos en un nuevo ingrediente argumental que introduce, tal vez pueda considerarse, al menos, un cierto movimiento de lo general a lo particular: el protector del asesino, que justificaba la libertad de Marzin porque la seguridad del país estaba por encima y el canalla podía ser útil como topo para la causa antiterrorista, termina muriendo en un tiroteo. ¿Es esa, por otra parte, una forma de justicia poética? Aunque el mensaje político del remake resulte algo tibio (a lo sumo, se llega a decir con ironía que "Guantánamo es un resort de lujo"), la paranoia post-11S funciona bien como telón de fondo y el cargo de conciencia de Jessica no es solo por sentirse responsable de la muerte de su hija, sino, en última instancia, también por la del agente, aunque encubriera a Marzin. Hay, por tanto, varios niveles de culpa y diferentes estratos de responsabilidad entre lo individual y lo colectivo que se cruzan debido a la recontextualización.

\section{LOS REAJUSTES DEL REMAKE: OTRA FORMA DE VIOLENCIA}

Como emprender un remake otorga una oportunidad espléndida de aprender de los errores o puntos débiles del filme previo, realzar sus aciertos y/o proponer nuevas ideas y lecturas, debería constituir una ventaja para el nuevo realizador. Por eso, es lógico que a menudo se enjuicien sus méritos y deméritos respecto al filme previo, pero más productivo que tasar ese lábil componente de la calidad intrínseca, resulta analizar, en cambio, el modo en que se encauza ese nuevo tema que se aborda. Confieso que resulta muy difícil, en una segunda fase de análisis, realizar el ejercicio de "suspender el cotejo" con el filme previo, además de que olvidarlo durante ese momento del proceso sería prácticamente un ejercicio de "crítica-ficción", pero creo que merece la pena el esfuerzo si se quiere ser constructivo. Habría, por tanto, que practicar un doble movimiento exegético de vinculación y desvinculación respecto al filme previo, y en este último paso creo que el tema del cargo de conciencia lo asume y resuelve el segundo filme de manera muy sugerente.

Billy Ray no encaja adecuadamente, desde luego, la trama amorosa con la criminal, lo cual fue un acierto de la novela de Sacheri al introducir un elemento metafictivo, y quizás la gran virtud, mediante concentración y potenciación respecto a su fuente literaria, de la película de Campanella. La razón puede estribar en que Ray renunció a ese componente metafictivo que el realizador argentino rescató muy bien del texto de Sacheri para articular su filme. De hecho, Campanella (en colaboración con el propio novelista, no lo olvidemos) no solo vinculó ambas tramas perfectamente, sino que constituye quizá su mayor mérito el haberlas equilibrado e 
integrado en lugar de deslindarlas. En el filme de Ray la historia amorosa parece un postizo (un retal mal cosido si volvemos a la idea matriz de texto como tejido) que llega a extremos ridículos en ciertos momentos, mientras que en la película argentina resulta conmovedora.

Así, lo más estremecedor de la propuesta de Campanella es que la violencia está íntimamente conectada con el amor: lo impide una y otra vez (la historia criminal se interpone entre los protagonistas cada vez que hay un conato de romance entre ellos, y él ha de exiliarse ante la amenaza del grupo paramilitar), pero finalmente lo espolea (Benjamín se decide a declararse a Irene tras descubrir lo que ha hecho Morales). La apuesta del remake consiste, en cambio, en que hay una forma de violencia más terrible, la que se practica contra uno mismo, de ahí que potencie el componente de la culpa y la absolución. Este giro se resuelve bien en el filme de Billy Ray, como hemos comprobado, tanto por vía simbólica (espejo quebrado en el ascensor para la culpa; pájaros volando en la casa apartada para la absolución) como por la posible asociación de cargos de conciencia colectivos y privados, de acuerdo con el nuevo contexto en el que se sitúa la historia y los reajustes de la violencia que se han efectuado. 


\section{BIBLIOGRAFÍA}

Acosta Larroca, Pablo. "El secreto de sus ojos: el mismo autor, la misma obra". Revista Atticus 9 (2009): 57-68.

ARENDT, Hannah (2006). Sobre la violencia. Madrid: Alianza.

BOYERO, Carlos. “Otro remake. ¿Y para qué?”. El País (14/04/2016).

Cascajosa, Concepción (2006). El espejo deformado. Visiones, secuelas y adaptaciones en Hollywood. Sevilla: Universidad de Sevilla.

DiLlon, Alfredo. "Sacheri por Campanella: del secreto a la pregunta de sus ojos". Question 58 (2018): 1-17.

FELIPE, Fernando de y GÓMEZ, Iván (2008). Adaptación. Barcelona: Blanquerna/Trípodos.

GARCÍA JAMBRINA, Luis. "De la palabra a la imagen: las relaciones entre literatura y cine". Poligrafías 3 (1998): 143-154.

GARCíA-REYES, David. "De luz y de sombras: los fantasmas de la memoria en El secreto de sus ojos". Archivos de la Filmoteca 73 (2017): 91-106.

GenetTe, Gérard (1989). Palimpsestos. La literatura en segundo grado. Madrid: Taurus.

Ivachow, Lilian Laura. "Pesos (de) ley”. El Amante 208 (2009): 18.

Karageorgon-BasteA, Christina. "Alegoría y restitución en El secreto de sus ojos". Revista Iberoamericana 262 (2018): 287-305.

LILLO, Gaston (2017). "El filme El secreto de sus ojos (2009) de Juan José Campanella y la novela El secreto y las voces (2002) de Carlos Gamerro". Wehr, Christian y Nitsch, Wolfram (eds.). Cine de investigación. Paradigmas de la revelación y del ocultamiento en el cine argentino. München: AVM: 139-155.

MALPARTIDA TIRADO, Rafael. "El secreto de sus ojos o cómo vivir una vida vacía: de la literatura al cine (Eduardo Sacheri/Juan José Campanella)". Revista de Crítica Literaria Latinoamericana 73 (2011): 353-376.

MARTíNEZ-CABEZA, Miguel y EspínOlA, Maica. "Suspense, culpa y cintas de vídeo. Caché/ Escondido de Michael Haneke”. Icono14 10/1 (2012): 149-163.

Navarro, Antonio José. “El secreto de sus ojos. La amada muerta”. Dirigido por 393 (2009): 17.

NoriegA, Gustavo. "Pretérito imperfecto, futuro perfecto”. El Amante 208 (2009): 16-17.

PEÑA ARDID, Carmen. "Rehacer cuerpos, construir identidades. La piel que habito (Pedro Almodóvar, 2011) y Tarántula (Thierry Jonquet, 1984)". Trasvases entre la literatura y el cine 2 (2020): 95-117.

PÉrez BOWIE, José Antonio y PARDO, Pedro Javier (eds.) (2015). Transescrituras audiovisuales. Madrid: Sial Pigmalión.

PERIS BLANeS, Jaume. "Desplazamientos, suturas y elusiones: el cuerpo torturado en Tiempo de Revancha, La Noche de los Lápices y Garage Olimpo”. Espéculo 40 (2008): s. p. 
PINKER, Steven (2003). La tabla rasa. La negación moderna de la naturaleza bumana. Barcelona: Paidós.

REPAR, Matías. “Entrevista a Eduardo Sacheri”. Clarín (18/08/2009).

ROA, Alana F. “De la compasión a la culpa: La traducción cultural de El Secreto de sus ojos”. deSignis 27 (2017): 147-155.

RobBen, Antonius (2002). "El miedo a la indiferencia: los temores de los combatientes sobre la identidad política de los civiles durante la guerra sucia argentina”. Koonings, Kees y Kruijt, Dirk (eds.). Las sociedades del miedo. El legado de la guerra civil, la violencia y el terror en América Latina. Salamanca: Universidad de Salamanca: 141-156.

RojAs, Eduardo. "Espejos del alma”. El Amante 208 (2009): 20-21.

SACHERI, Eduardo (2009). El secreto de sus ojos. Madrid: Alfaguara.

SÁnchez Noriega, José Luis (2000). De la literatura al cine. Teoría y análisis de la adaptación. Barcelona: Paidós.

STAM, Robert (2014). Teoría y práctica de la adaptación. México: UNAM.

Wolf, Sergio (2001). Cine/Literatura. Ritos de pasaje. Buenos Aires: Paidós.

Wright, Lawrence (2017). La torre elevada. Al-Qaeda y los origenes del 11-S. Barcelona: Penguin Random House.

ZECCHI, Barbara (2006). "Estrategias de elisión, inscripción y desexuación en la representación cinematográfica de la violencia contra la mujer". García Selgas, Fernando J. y Romero Bachiller, Carmen (eds.). El doble filo de la navaja: violencia y representación. Madrid: Trotta: 107-128.

ZECCHI, Barbara (2012). "Introducción. La adaptación multiplicada". Zecchi, Barbara (ed.). Teoría y práctica de la adaptación fülmica. Madrid: Editorial Complutense: 19-62.

ŽIŽEK, Slavoj (2009). Sobre la violencia. Seis reflexiones marginales. Barcelona: Paidós.

\section{FILMOGRAFÍA}

CAmpanella, Juan José (2009). El secreto de sus ojos. Argentina/España: 100 Bares/Tornasol Films/Haddock Films/Telefé/TVE/Canal+España.

RaY, Billy (2015). Secret In Their Eyes. Estados Unidos: Gran Via Productions/IM Global. 